\title{
Furtherance in Splicing Technique of Optical Fiber Communication
}

\author{
Jayant R. Nandwalkar, Dnyandeo J. Pete
}

\begin{abstract}
The improvement in technology over long distance communication using optical fiber has been regulated over past few decades, and it took drastic enhancement in one of the major parameter for joining two OFC cable (splicing). The different experiments performed in order to bring about the result that can give nearly $\mathrm{OdB}$ splice loss when there is shifting of entire set up of Optical Fiber Communication. The splicing loss is created by the joining of two SMF using fiber optic fusion splicing. The objective of this paper is to determine the low splice loss in joining two single mode or multimode optical fiber, such that long distance communication that required multiple infrastructure assembly for its operational unit can be made relocatable as there is large investment and material and electronic circuitry is associated to it. Therefore to reduce that cost we have sets of analysis that splicing loss can be reduced to OdB for SMFSMF end face connection or at least no improvement in splice losses while relocation of OFC infrastructure from one place to other place as the result of the tested experiment. Based on experiment conducted we came to conclusion that with essential requirements for establishing a low-loss and high-speed communication line using optical fibers, the need for quality of splicing technology along with perfect core alignment angle is required to reduce splice loss, such that the infrastructure can be shifted to many different location without any additional cost of new material and new resources. The exact measurement of splice loss can be insured by another set of formula which we came across during the experimental performance.
\end{abstract}

Index Terms - optical fiber communication (OFC), fusion splicing, loss measurement, single mode fiber (SMF), fiber loss and distance estimate.

\section{INTRODUCTION}

In the late $18^{\text {th }}$ century the optical communication came to an existence for more efficient and accurate communication by the French inventor. In the month of April 1977 testing deployment of the world's first live telephone traffic through a fiber-optic system was introduced that has speed running at 6 Mbps. Later it followed in invention of the Bell in May 1977, with an optical telephone communication system installed in the downtown area, covering a distance of 1.5 miles (2.4 kilometers). Each optical-fiber pair carried the equivalent of 672 voice channels and was equivalent to a DS3 circuit. Today more than 80 percent of the world's long-distance voice and data traffic is carried over opticalfiber cables that are connecting the global world faster $\left(5^{\text {th }}\right.$ Generation Technology) than ever expected [7].

Revised Manuscript Received on February 05, 2020.

* Correspondence Author

Jayant R. Nandwalkar, Research Scholar (Student Member, IEEE, DMCE), , Department of Electronics Engineering, Datta Meghe College of Engineering, Sector-3, Plot-98, Airoli, Navi Mumbai. 400708 University of Mumbai, Maharashtra State, India

Dnyandeo J. Pete, Professor \& Head, Department of Electronics Engineering, Datta Meghe College of Engineering, Sector-3, Plot-98, Airoli, Navi Mumbai. 400708 University of Mumbai, Maharashtra State, India

(C) The Authors. Published by Blue Eyes Intelligence Engineering and Sciences Publication (BEIESP). This is an open access article under the CC BY-NC-ND license (http://creativecommons.org/licenses/by-nc-nd/4.0/)
Optical fiber communication system is similar in basic concept to any type of communication system. A block schematic of a general communication is the building blocks circuit of which is to convey the signal from the information source over the transmission medium to the destination.

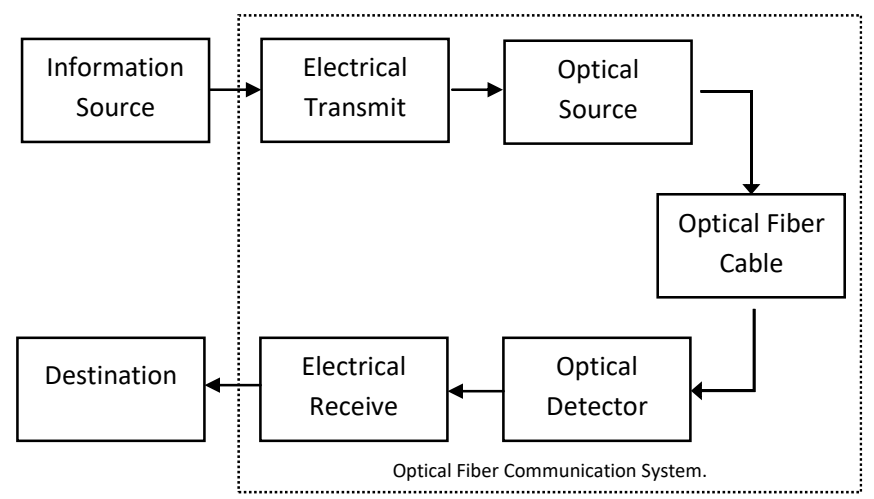

Fig.1 Block Diagram of OFC System

The communication system therefore consists of a transmitter or modulator linked to the information source, the transmission medium, and a receiver or demodulator at the destination point.

During 1970-1985 the transmission loss along with splice loss was taken into consideration to improve the life span, accuracy and protection of the SMF joints. The new technology, splicing technology in fusion splicing was discussed with few bench marks set for further expansion in optical network infrastructure and many new emerging field [1]. The further enhancement the splicing structure, core alignment there was certain range of frequency bandwidth was determine with respect to cutting angle position of two SMF to avoid miss alignment[2]-[4]. The standard related to optical fiber splicing and splice loss measurement were not appropriate for certain range and standard range methods and specification were involved with SMF-SMF to match the previous sets to keep track on the progress [3]. There always a chance of misalignment in core diameter adjustment, angle of face side of splice which is need to precise in order to obtain accurate result which can be effected by many certain parameters like altitude, slope, marshy region, might affect the splice loss [5].

Material used for optical fiber cable is glass silica or plastic with very small diameter like as hair. Optical fiber is mean of transfer of light signal from one end to other end of fiber. Visible light lasers are used to test continuity of fiber called as visual continuity testing method, using which one can detect or breaks or cracks in fiber. Optical Return Loss (ORL) or Overall Return Losses (ORL) is actually the total amount of light reflected from break or discontinuity of fiber. For this measurement ORL meter can be used.

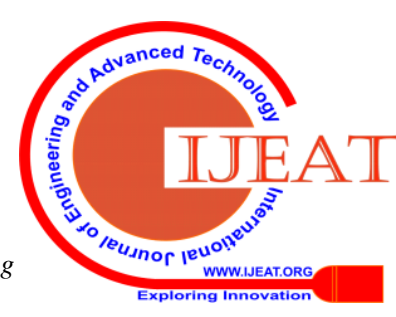


Furtherance in Splicing Technique of Optical Fiber Communication

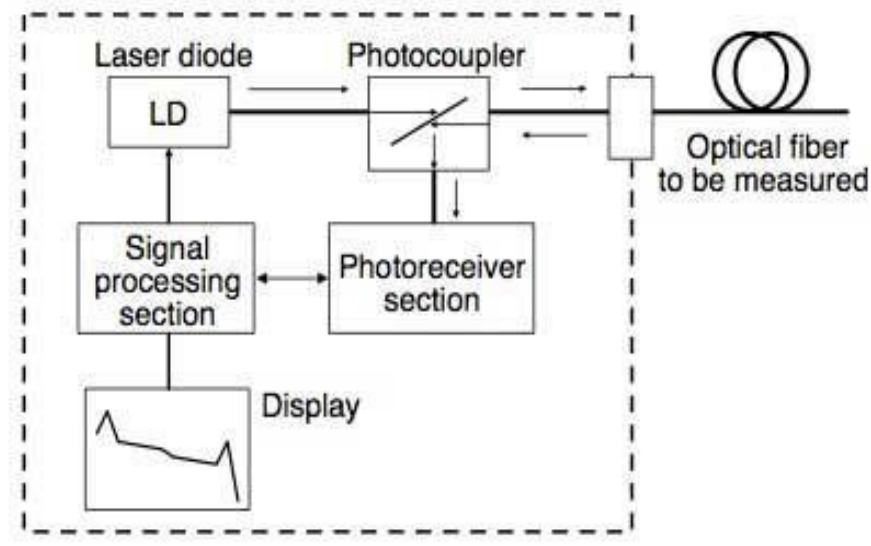

Fig.1 A Block Diagram of Optical Time Domain Reflectometer

Optical Time Domain Reflectometer (OTDR): OTDR send / transmit / insert the light into the fiber with / at a wide range of width pulse and then measure the reflected / returned light. Then by comparing or / by complex computation, distances of fault are determined which are then calibrated in terms of losses. Operating concept can be understand from fig. 1A. In 2015 the splice losses measured by OTDR were 3-10 $\mathrm{dB}$.

Generally OTDR is referred than LSPM (Light Source \& Power Meter) or OLTS (Optical Loss Test Set) because it gives individual loss component measurement.

\section{SPLICING TECHNOLOGY}

Fusion splicing is a technique by which the two fibers are permanently or semi permanently soldered together. Fiberoptic cables have to be spliced together for a number of reasons to extend the cable to a particular length. Another reason might involve joint break, in which case a fiber-optic cable might have been ripped apart due to trenching work. The network installer might have in his inventory several fiber-optic cables, but none long enough to satisfy the required link length. Situations such as this often arise because cable manufacturers offer cables in limited length usually 1 to $6 \mathrm{~km}$. A link of $10 \mathrm{~km}$ can be installed by splicing several fiber-optic cables together. The installer can then satisfy the distance requirement and avoid buying a new fiber-optic cable. Splices might be required at building entrances, wiring closets, couplers, and any point between a two terminal A \& Terminal B. Connecting two fiber-optic cables requires precise alignment of the mated fiber cores or spots in a single-mode fiber (SMF) optic cable. This is required so that nearly all the light is coupled from one fiber-optic cable across a junction to the other fiber-optic cable. Actual contact between the fiber-optic cables is not even mandatory there should only be proper core connection. There are mainly two principal types of splices faces [10].

A. Fusion splicing: Fusion splices use an electric arc to weld two fiber-optic cables together. The process of fusion splicing involves using localized heat to melt or fuse the ends of two optical fibers together

B. Mechanical Splicing: is done by the use of jumpers/connector.
Table:1 Formulae for the splice loss

Splice loss $=\frac{{\text { splice } l o s s_{\mathrm{A} \text { to } \mathrm{B}}+\text { splice } \text { loss }}_{\mathrm{B} \text { to } \mathrm{A}}}{2}$
Splice loss $=(\max$ loss in $\mathrm{dB}) *($ Total distance in meters $)$

For proper splicing process the following steps are accumulated:

- $\quad$ Smooth faced end of the fibers (properly cleaved).

- Cleaning of outer cover of the at the joints area.

- Alignment of core manually or in automated manner.

- Adding protection sleeves to the freshly joint section.

The recent fact of the splice stated that, Splices can also be used as optical attenuators if there is a need to attenuate a high-powered signal. Splice losses of up to $10.0 \mathrm{~dB}$ can be programmed and inserted into the cable if desired. This way, the splice can act as an in-line attenuator with the characteristic no reflectance of a fusion splice. Typical fusion-splice losses can be estimated at $0.02 \mathrm{~dB}$ for lossbudget calculation purposes. Mechanical splices are easily implemented in the field, require little or no tooling, and offer losses of about 0.5 to $0.75 \mathrm{~dB}$ [7]. Therefore the above process is been used to determine the experiment and to obtain the desired results in the process.

\section{EXPERIMENTAL}

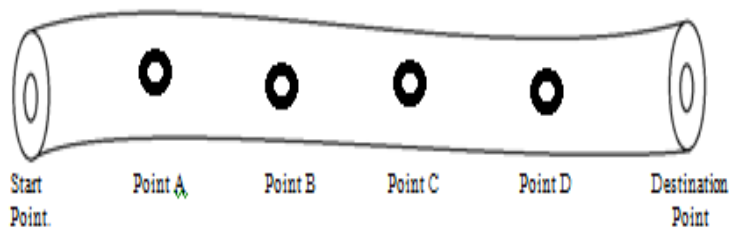

Fig-2 Indication of splice joints

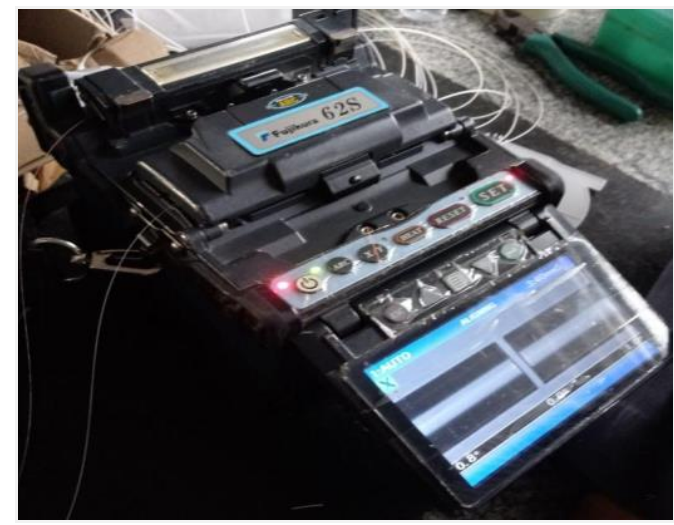

Fig-3 Splice arrangement Fujikura 62S splicer

\section{A. Experiment 1}

The experiment was done in order to perform the short distance splicing that is used by local LAN, TV and Internet provider. 
The optical fibers are used here for sending and receiving the high speed data/information over shorter distance. This experiment primarily focuses on the short or zonal level connection of new unit that is to be made operational for the use of transmission \& receiving of data signals from one place to another by the use of optical fibers. As we all know that, for splicing two SMF cable we required a splicer, fiber cleavers and optical fiber cables. For short distance splicing we made use of 1000 meters optical cable. The parameters for end to end splicing joint done are listed in the table. For splicing we have made use of traditional fusion splicing technique method by the use of Fujikura 62S splicer along with CT50 fiber cleaver.

The CT50 changes the position of the cleaving blade automatically and in accordance with the condition of the cleaving state of optical fibers on a fusion splicer through wireless communication.

We have determined the length of wire that was used to be 1000 meters and point A to D are the respective joints where splicing is been done. The total distance of the working wire is $2.824 \mathrm{~km}$. with both end connected to CAT-6 LAN cable at one end and local host services base at another. (CAT-6 cable is twisted pair cable used for Ethernet connections specified for $250 \mathrm{MHz}-500 \mathrm{MHz}$, it is good cable which reduces the cross talk) The main purpose of the experiment is to make the individual joints along the start to end to be done very accurately in order to determine the no loss or OdB loss throughout the joint. The joint splice loss was detected by splicer machine and total loss was then verified using Optical Time Domain Reflectometer (OTDR).

Table 2. Information of the splicing location in experiment 1

\begin{tabular}{|c|c|c|c|}
\hline $\begin{array}{c}\text { Fiber File } \\
\text { Number }\end{array}$ & Wave length(nm) & Joint location & Distance \\
\hline Fiber001 & 1550 & A & $0.213 \mathrm{~km}$ \\
\hline Fiber001 & 1550 & B & $0.277 \mathrm{~km}$ \\
\hline Fiber001 & 1550 & C & $0.286 \mathrm{~km}$ \\
\hline Fiber001 & 1550 & D & $0.324 \mathrm{~km}$ \\
\hline
\end{tabular}

\section{B. Experiment 2}

As discussed in experiment-A, similar type of experiment was conducted in order to determine the long distance high speed connection using optical fiber communication. This communication makes the use of two pier cables in which the inner core of the cables consists of 2, 4, 6, 24, 36, 48, 98 threads. These are regularly used for all networks, where as 96, $144 \& 288$ core cables (threads) are used for National Long Distance (NLD) routes. In this NLD routes there are network towers that are used for mobile network and other transfer of data, the failure in this can result in heavy penalty in terms of monetary and loss of data to user client and service provider. As per long distance communication is concern to avoid the network loss due to any parameters we make use of CCN based network topology that include ring, mesh \& star topology. In this experiment we made use of composite fiber and link joint connectors in order to determine different loss associated to the splicing. Therefore similar process was performed in order to determine the long distance optical communication.
Table 4. Information of the splicing location in experiment 2

\begin{tabular}{|c|c|c|c|}
\hline Fiber File Number & Wave length(nm) & Joint location & $\begin{array}{c}\text { Distance } \\
(\mathrm{m})\end{array}$ \\
\hline Fiber002 & 1550 & A & $417.37 \mathrm{~m}$ \\
\hline Fiber002 & 1550 & B & $1230.42 \mathrm{~m}$ \\
\hline Fiber002 & 1550 & C & $2910.11 \mathrm{~m}$ \\
\hline Fiber002 & 1550 & D & $5605.79 \mathrm{~m}$ \\
\hline Fiber002 & 1550 & E & $7377.39 \mathrm{~m}$ \\
\hline Fiber002 & 1550 & F & $9220.46 \mathrm{~m}$ \\
\hline Fiber002 & 1550 & G & $12932.12 \mathrm{~m}$ \\
\hline
\end{tabular}

\section{RESULT \& DISCUSSION}

The parameters represented in table 3 \& tables 5 actually determine the splice loss and total loss in fiber were obtained while performing the experiment at location with the proper use of the machinery. We have visited to all the different location to get the reading and observed the following reading which clearly shows the result given bellow.

Table3. Observed Splice loss and Total loss at joints in experiment 1

\begin{tabular}{|c|c|c|c|c|}
\hline Joint & A & B & C & D \\
\hline $\begin{array}{c}\text { Splice loss at individual joint } \\
(\mathrm{dB})\end{array}$ & 0.01 & 0 & 0.02 & 0 \\
\hline Total loss at individual joint(dB) & 0.04 & 0.04 & 0.26 & 0.5 \\
\hline
\end{tabular}

\section{Experiment No. 01}

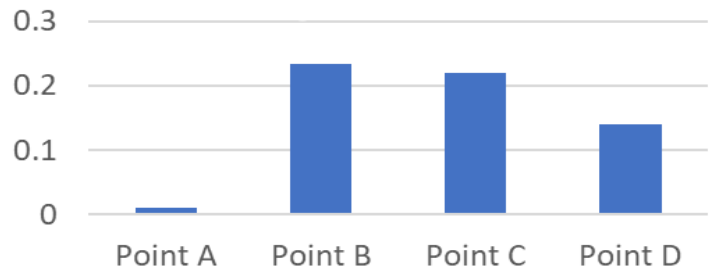

- Splice loss at an individual joint (dB)

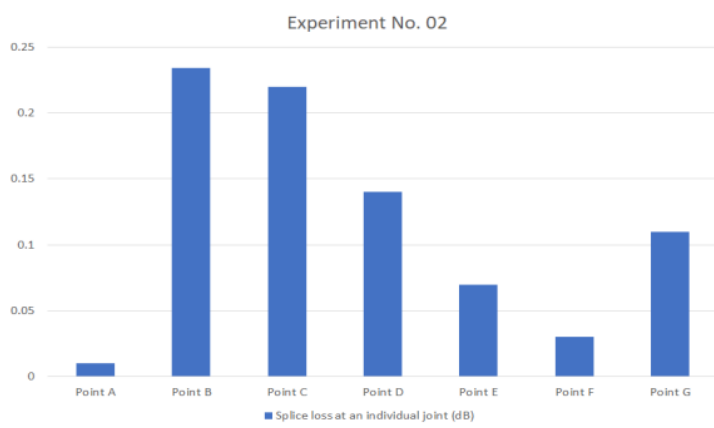

Fig-4 Graphical Representation of losses from experiment 1 


\section{Furtherance in Splicing Technique of Optical Fiber Communication}

Table5. Observed Splice loss \& Total loss at joints in experiment 2

\begin{tabular}{|c|c|c|c|c|c|c|c|}
\hline Joint & A & B & C & D & E & F & G \\
\hline $\begin{array}{c}\text { Splice loss } \\
\text { at the } \\
\text { individual } \\
\text { joint (dB) }\end{array}$ & 0.01 & 0.234 & 0.22 & 0.14 & 0.07 & 0.03 & 0.11 \\
\hline $\begin{array}{c}\text { Total Loss } \\
\text { at the } \\
\text { individual } \\
\text { joint(dB) }\end{array}$ & 0.248 & 3.062 & 4.338 & 8.012 & 8.487 & 9.015 & 11.237 \\
\hline
\end{tabular}

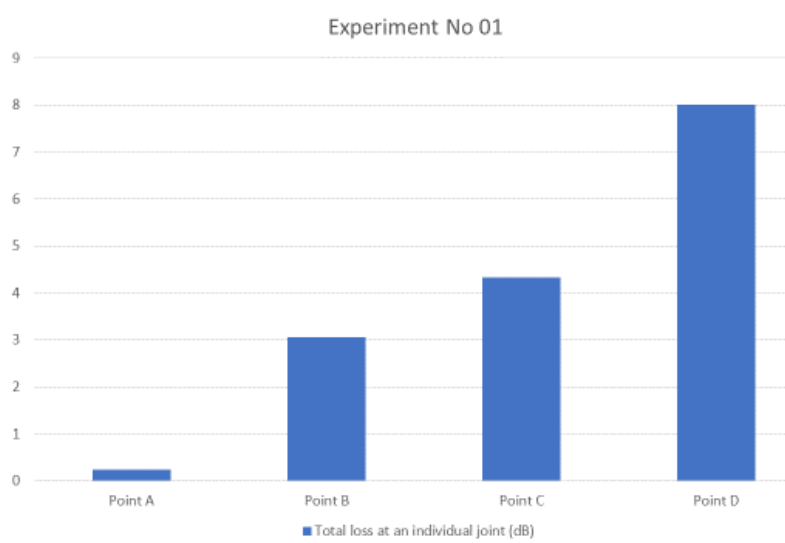

The figure 6 indicates the total splicing joint and associated to the optic fiber over the certain distance. The red mark in the wideband or bandwidth present in the

Experiment No. 02

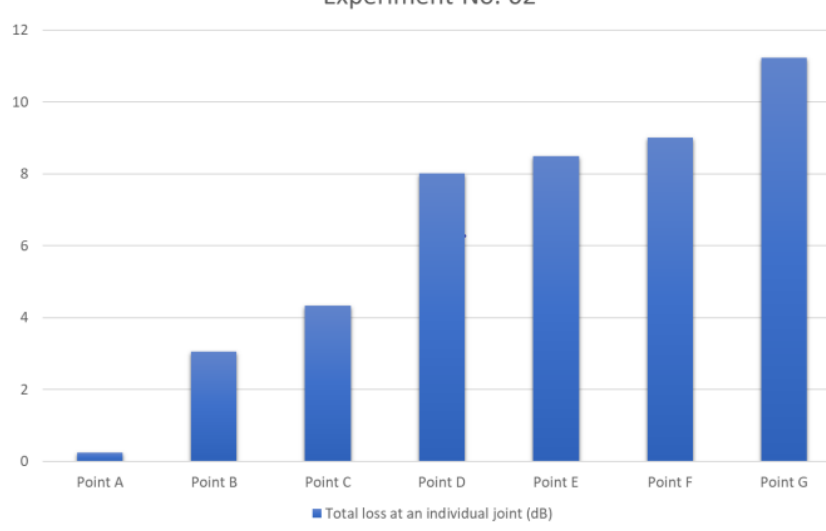

Fig-5 Graphical Representation of losses from experiment 2

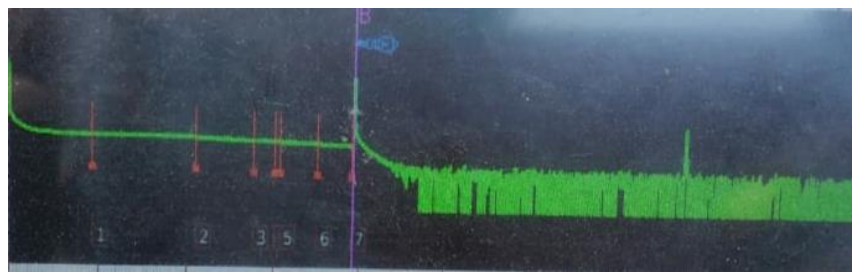

Fig-6 Result of Optical Time Domain Reflectometer (OTDR) on Screen

image indicates the splice joint and splice loss, wherein the other half indicate the presence of noise as there is no association of the fiber in the region. As fiber had get into the joint we have seen that there is the phase shift in the Reflectometer depending upon the fact the purity of the fiber and pass band for optical network plays an important role, Else if we can obtain more noise introduce in the fiber [8,9]

\section{CONCLUSION}

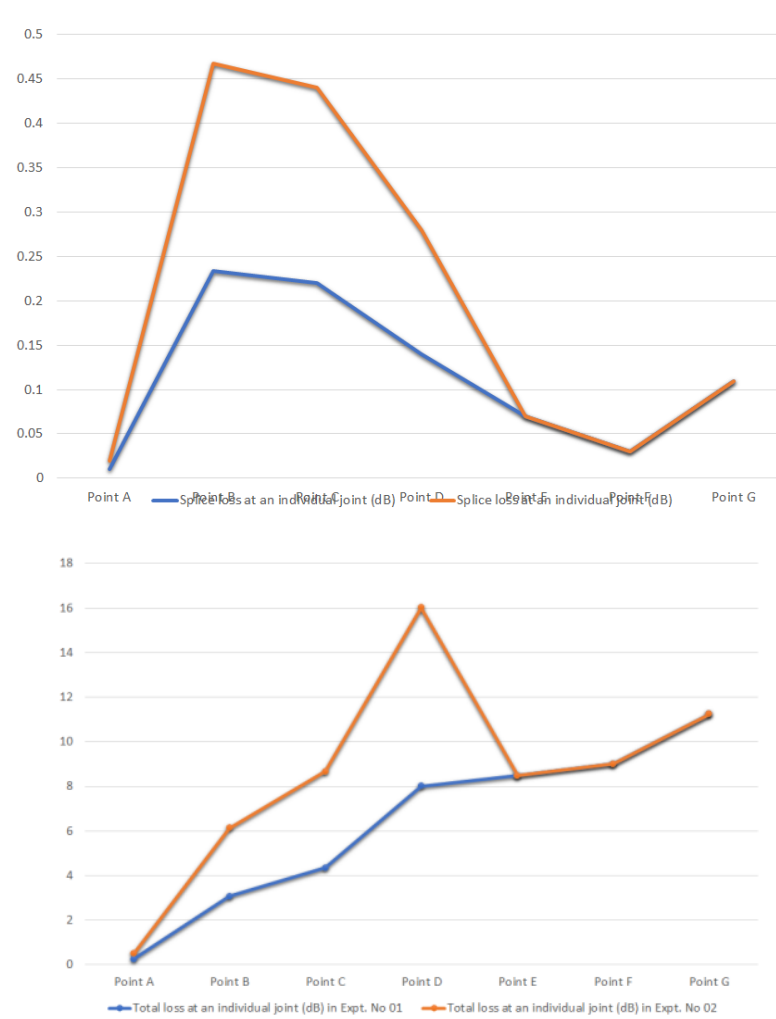

Fig. 7 Coparison by graphs for both experiments

In this experimental work of splice loss and total loss in the optical fiber cable the observation came to the conclusion that in Optical Time Domain Reflectometer (OTDR) the reading that are taken total loss is the combination of other losses that include bending loss, refractive loss, propagation loss, absorption loss, scattering and other losses but the splice loss remain the same as it was been observed before. Therefore, as our aim of the experiment was to prove that in the total losses of fiber links the splicing loss is zero or very negligible which may not be able to recognise (Briefed from fig.7), so that we can transfer the infrastructure or the entire optical fiber cable communication setup can be moved to different region without any additional splice loss. On other hand we also came to know the fact that if the inner core of fiber that is made up of glass, if refractive index is dropped or changed by chemical factor (doping) or by heat treatment to fiber the total loss also be reduced and additional cost that are used on electronic component to retrieve the signal can be reduced.

\section{ACKNOWLEDGEMENT}

The authors would like to thank the editors, reviewers and Industrial associates for guidance and providing technological and service support to obtain this result.

Authors would also like to thanks the following members for their kind administrative \& technical support during onsite practical sessions. 

a) Somnath Dhaktode (Intech Online PVT LTD, Thane)
b) Rajesh Shukla (Yogiraj Cable/Den service Provider)
c) Jagruti \& Kamal fibre Networks, Andheri west.

\section{REFERENCES}

1. Optical Fiber Fusion Splicer, Noriyuki Kawanishi1

2. Ultra-long Distance Distributed Intrusion Detecting System Assisted With In-line Amplification Volume 9, Number 2, April 2017, Macheng Lai Kuan Peng Yiyang Luo Xiaolei Li Yanpeng Li Fan Ai Deming Liu Qizhen Sun, DOI: 10.1109/JPHOT.2017.2688471 1943-0655 (C) 2017 IEEE

3. Is That Splice Really Good Enough? Improving Fiber Optic Splice Loss Measurement, NEMI Fiber Optic Splice Improvement Project Members: J. Meitzler, 3SAE; L.Wesson, Aurora; P. Arrowsmith and R. Suurmann, Celestica; M. Rodriguez, Jabil; D. Gignac, Nortel Networks; S. Pradhan, Sanmina-SCI; J. Garren and J. Johnson, Solectron; T. Watanabe, Sumitomo Electric; and E. Mies, Vytra

4. Setting SpliceSpecifictaion for Single-Mode Fiber cables White Paper, David Gibb, Corning, Optical Fibers, Richard Grigsby, Corning Cable System, Allan Berney, Corning Cable System, Mary Dcox, Corning Optical Fibers., WP7114 issued: August 2001 ISO9001 Registered

5. Modeling the splice loss of single-mode optical fibers affected by altitude Ziru Cui1, Student Member, IEEE, Chaowei Yuan1 1School of Information and Communication Engineering, Beijing University of Posts and Telecommunications, Beijing 100876, China Corresponding author: Chaowei Yuan (e-mail: yuancw2000@bupt.edu.cn).

6. The Analysis of Fusion Splice Technique on Single Mode Fiber Optic, Norazlina Ahmad politeknik Kota Kinabalu Sabah, Malaysia, Azman Talib, Electrical Engineering Department, politeknik politeknik Kota Kinabalu Sabah, Malaysia, azmant@polikk.edu.my

7. Fiber-Optic Technologies, by Vvek Alwayn, Cisco Press, Date: 23, 2004

8. Design of All-Optical Modulation Format Converter From One 8PSK to Two QPSK Signals Based on Phase Sensitive Amplification in Elastic Optical Network. HONG LIU , (Student Member, IEEE), HONGXIANG WANG , (Member, IEEE), JIABIN CUI , (Student Member, IEEE), AND YUEFENG JI , (Senior Member, IEEE) State Key Laboratory of Information Photonics and Optical Communications, School of Information and Communication Engineering, Beijing University of Posts and Telecommunications, Beijing 100876, China Corresponding author: Yuefeng Ji (jyf@bupt.edu.cn)

9. Demonstration of Ultra Wideband Phase-Sensitive Fiber Optical Parametric Amplifier Rohit Malik, Aleš Kumpera, Magnus Karlsson, Senior Member, IEEE, and Peter A. Andrekson, Fellow, IEEE, IEEE PHOTONICS TECHNOLOGY LETTERS, VOL. 28, NO. 2, JANUARY 15, 2016

10. Optical Fiber Communications Principles and Practice

Third edition, published 2009 John M. Senior assisted by M. Yousif Jamro.

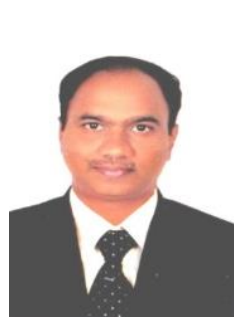

\section{AUTHORS PROFILE}

Mr. Jayant Ramesh Nandwalkar, (Research Scholar, Student member IEEE ) LMISTE, M.E. (EXTC) Assistant Professor, Department of Electronics Engineering Datta Meghe College of Engineering, Airoli Navi Mumbai. University of Mumbai Email-id: jayantnandwalkar@ieee.org

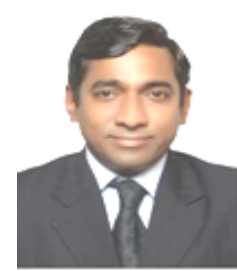

Dr. Dnyandeo J. Pete, (Ph.D. in VLSI Technology rom Nagpur University. M.Tech. from IIT Bombay) Professor \& Head, Department of Electronics ngineering, , Datta Meghe College of Engineering, Airoli, Navi Mumbai. University of Mumbai 